Research Paper

\title{
Gadd45b is a Novel Mediator of Neuronal Apoptosis in Ischemic Stroke
}

Bin Liu\#, Yan-hong Zhang, Ying Jiang, Long-ling Li, Qian Chen, Guo-qian He, Xiao-dan Tan, Chang-qing $\mathrm{Li}^{\bowtie}$

Department of Neurology, The Second Affiliated Hospital of Chongqing Medical University, Chongqing, China

\# Current Addresses: Department of Neurology, Shandong Provincial Qianfoshan Hospital, Shandong University, Jinan, China

$\bowtie$ Corresponding author: E-mail:licq9217@cqmu.edu.cn

(C) 2015 Ivyspring International Publisher. Reproduction is permitted for personal, noncommercial use, provided that the article is in whole, unmodified, and properly cited. See http://ivyspring.com/terms for terms and conditions.

Received: 2014.06.04; Accepted: 2015.01.12; Published: 2015.02.08

\begin{abstract}
Apoptosis plays an essential role in ischemic stroke pathogenesis. Research on the process of neuronal apoptosis in models of ischemic brain injury seems promising. The role of growth arrest and DNA-damage-inducible protein 45 beta (Gadd45b) in brain ischemia has not been fully examined to date. This study aims to investigate the function of Gadd45b in ischemia-induced apoptosis. Adult male Sprague-Dawley rats were subjected to brain ischemia by middle cerebral artery occlusion (MCAO). RNA interference (RNAi) system, which is mediated by a lentiviral vector (LV), was stereotaxically injected into the ipsilateral lateral ventricle to knockdown Gadd 45b expression. Neurologic scores and infarct volumes were assessed $24 \mathrm{~h}$ after reperfusion. Apoptosis-related molecules were studied using immunohistochemistry and Western blot analysis. We found that Gadd45b-RNAi significantly increased infarct volumes and worsened the outcome of transient focal cerebral ischemia. Gadd45b-RNAi also significantly increased neuronal apoptosis as indicated by increased levels of Bax and active caspase-3, and decreased levels of $\mathrm{Bcl}-2$. These results indicate that Gadd45b is a beneficial mediator of neuronal apoptosis.
\end{abstract}

Key words: MCAO, Gadd45b, BDNF, Apoptosis

\section{INTRODUCTION}

Ischemic stroke is one of the leading causes of death and long-term disability worldwide. Considering the essential role of apoptosis in the pathogenesis of ischemic stroke, a more detailed understanding of the mechanisms involved will have a substantial effect in the optimization and development of treatment strategies. Subsequent to acute ischemic stroke, an early response emerges in the gene expression of key modulators of apoptosis, such as the Bcl-2 family. The release of pro-apoptotic proteins from the mitochondria induces the activation of caspases and other genes that aggravate apoptotic cell death $[1,2]$.

Growth arrest and DNA-damage-inducible protein 45 beta (Gadd45b) is originally recognized as an important factor in DNA repair, apoptosis, cell sur- vival, growth arrest, and possibly DNA demethylation. Several studies on non-neuronal cells have suggested Gadd45b as an anti-apoptosis gene [3,4]. Gadd $45 \mathrm{~b}$ was identified as an intrinsic neuroprotective molecule in retinal ganglion cells $[5,6]$. It's not clear whether Gadd45b was involved in apoptosis induced by ischemic stroke. This study aims to evaluate the effects of Gadd45b downregulation in neuronal apoptosis after cerebral ischemia.

\section{MATERIALS AND METHODS}

\section{Animals}

Adult male Sprague-Dawley (SD) male rats (230-300g) were purchased from the Experimental Animal Center of Chongqing Medical University. 
Rats were group housed (five rats per cage) in quiet in a room maintained at $21-22{ }^{\circ} \mathrm{C}$ on a $12 / 12-\mathrm{h}$ light/dark cycle, and allowed free access to food and water during the study. All animal procedures were reviewed and approved by the Institutional Animal Care and Use Committee at the Chongqing Medical University and were performed strictly in accordance with the "Guiding Principles for Research Involving Animals and Human Beings".

A total of 186 rats were included in the study. Data are reported on 104 animals. Eighty-two were excluded from the study due to no neurologic abnormalities (16) or death (66). Rats were randomly assigned to groups: sham $(n=14)$; MCAO $(n=30)$; Lentiviral vector (LV)-control (ischemia and LV-Control, $\mathrm{n}=30$ ), and LV-shGadd45b (ischemia and LV-shGadd45b, n=30).

\section{Transient MCAO in Rats}

To induce transient focal cerebral ischemia in rats, middle cerebral artery occlusion (MCAO) surgery was performed as described previously [7]. Rats were anesthetized using 3.5\% chloral hydrate (350 $\mathrm{mg} / \mathrm{kg}$, ip) and right common carotid artery (CCA) was surgically exposed by a midline neck incision. Right CCA was ligated distally and external carotid artery (ECA) was ligated proximally to ECA and internal carotid artery (ICA) bifurcation. A $30 \mathrm{~mm}$ length of nylon filament (diameter $0.25 \pm 0.03 \mathrm{~mm}$ ) was gently inserted into the lumen of ICA from right ECA. Afterwards, reperfusion was established by withdrawal of the nylon filament at $2 \mathrm{~h}$ after ischemia. In the sham group, rats underwent the same surgical procedures without occlusion of the right CCA. Rats were then returned to their cages and body temperature were kept at $(37 \pm 0.5){ }^{\circ} \mathrm{C}$.

\section{Gadd45b-shRNA Injection}

LV pLKD.UBC.GFP.U6.shRNA was generated and purchased from Neuron Biotech (Shanghai, China). The prepared rat Gadd45b-shRNA sequence was 5-CGA CAA CGC GGU UCA GAA GUU-3 (sense) and 5-PCU UCU GAA CCG CGU UGU CGUU-3 (antisense). Seven days before MCAO surgery, $4 \mu \mathrm{l}$ of concentrated viral solution (containing Gadd45b-shRNA) was stereotaxically delivered into the ipsilateral lateral ventricle (coordinates from bregma: AP $1.1 \mathrm{~mm}, \mathrm{ML} 0.8 \mathrm{~mm}$, DV $4.2 \mathrm{~mm}$ from the pial surface). The control rats were also injected with the same dose of lentivirus without Gadd45b-shRNA.

\section{Detection of Virus Delivery}

Green fluorescent protein (GFP) was observed in brain section under a fluorescence microscope for the detection of virus delivery. To determine the proper therapeutic titer, Gadd45b mRNA and protein ex- pression was examined through real-time PCR and immunohistochemistry. The most appropriate therapeutic titer was used in the following study.

\section{Sample Processing}

The rats were killed $24 \mathrm{~h}$ after reperfusion, and the brains were quickly removed by neck breaking to collect the cerebral cortex for immunohistochemistry, Western blot analysis, real-time PCR and TTC staining.

\section{RNA Isolation and Real-Time PCR}

Animals were anesthetized using 3.5\% chloral hydrate $(350 \mathrm{mg} / \mathrm{kg}$, ip) $24 \mathrm{~h}$ after MCAO. Total RNA from ipsilateral ischemic penumbra was harvested for the assay of Gadd45b and BDNF mRNA levels. The procedure was similar to that in our previous study [8]. The sequence for Gadd45b forward primer was 5'-TGA TCC AAT CGT TCT GCT GC-3') and the reverse primer was $5^{\prime}$-CGT TTG TGC CTA GAG TCT CTG C $-3^{\prime}$. The sequence for BDNF forward primer was 5'-TGT CCG AGG TGG TAG TAC TTC ATC-3' and the reverse primer was 5'-CAT GCA ACC GAA GTA TGA AAT AAC C- $3^{\prime}$. The sequence for $\beta$-actin forward primer was $5^{\prime}$-CGT TGA CAT CCG TAA AGA CCT C-3' and the reverse primer was 5'-TAG GAG CCA GGG CAG TAA TCT-3'. The real-time PCR protocol was $95^{\circ} \mathrm{C}$ for $5 \mathrm{~min}$, followed by 40 cycles of $95^{\circ} \mathrm{C}$ for $10 \mathrm{~s}$ and $60^{\circ} \mathrm{C}$ for $30 \mathrm{~s}$. Cycle threshold (Ct value) was acquired from the software provided by the manufacturer. A relative quantity was calculated using the 2- $\Delta \Delta C T$ method [9] for each sample.

\section{Immunohistochemistry}

Rats were anesthetized using 3.5\% chloral hydrate $(350 \mathrm{mg} / \mathrm{kg}$, ip) $24 \mathrm{~h}$ after MCAO. Paraffin sections were prepared as previously described [8]. In brief, sections ( $\mathrm{n}=5$ for each group) were incubated with primary antibodies (rabbit anti-Gadd45b, 1:80; rabbit anti-BDNF, 1:200; rabbit anti-Bax, 1:100; and rabbit anti-Bcl-2, 1:100; all from Santa Cruz, USA) overnight at $4{ }^{\circ} \mathrm{C}$. Afterwards, sections were blocked with normal serum for $30 \mathrm{~min}$ at $37^{\circ} \mathrm{C}$. Then, the samples were incubated with goat anti-rabbit IgG for $30 \mathrm{~min}$ at $37^{\circ} \mathrm{C}$. Positive activity was revealed with diaminobenzidine. Confocal images were taken with a Nicon microscope. Gadd45b, BDNF, Bax and Bcl-2 expression were quantified using NIH ImageJ software. Immunopositive cells were quantified in sequential fields of $1 \mathrm{~mm}^{2}$ at ipsilateral ischemic penumbra in five animals selected randomly from each group. The number of neurons per field for each sample was the average of 20 consecutive objects in 4 sections/case by an investigator who was blinded to this study. 


\section{Western Blot Analysis}

Six animals in each group were sacrificed $24 \mathrm{~h}$ after reperfusion, and the rat brain tissues were extracted from ipsilateral ischemic penumbra. Western blot analysis was performed as described previously [8]. Anti-Bax (1:200, Santa Cruz, USA), anti-Bcl-2 (1:200, Santa Cruz, USA), anti-BDNF (1:200, Santa Cruz, USA), anti-cleaved caspase-3 (1:500, Cell Signaling Technology), and anti-GAPDH (1:2000; Santa Cruz, USA) were used as primary antibodies. The blots were subjected to gel formatter (BIO-RAD) and quantified through Quantity One analysis. GAPDH was used as an internal loading control.

\section{Neurological Deficits}

Neurological deficits were determined $24 \mathrm{~h}$ after stroke according to a neurological grading score [10]. The evaluator was blinded to the experimental treatment. Briefly, neurological deficits was scored as follow: $0=$ no observable deficit, $1=$ torso flexion to the right side, $2=$ spontaneous circling to the right side, $3=$ falling to the right side and $4=$ no spontaneous movement.

\section{Measurement of Infarct Volume}

The rats were euthanized under anesthesia $24 \mathrm{~h}$

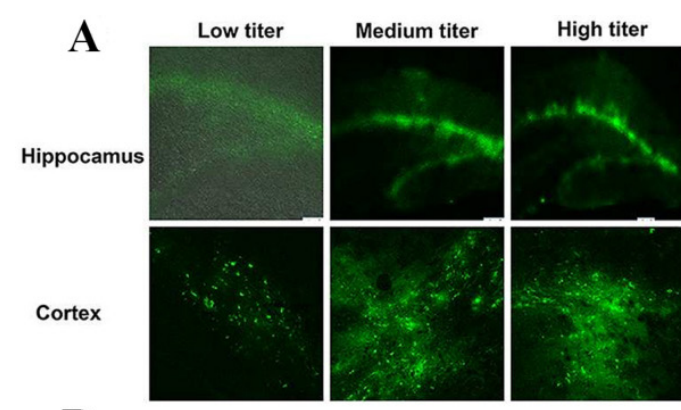

B

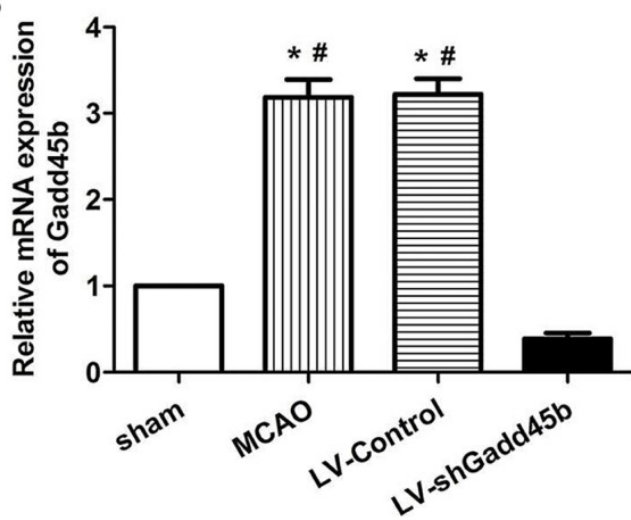

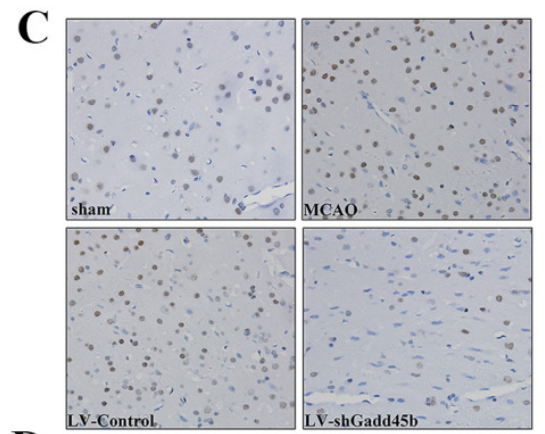

D

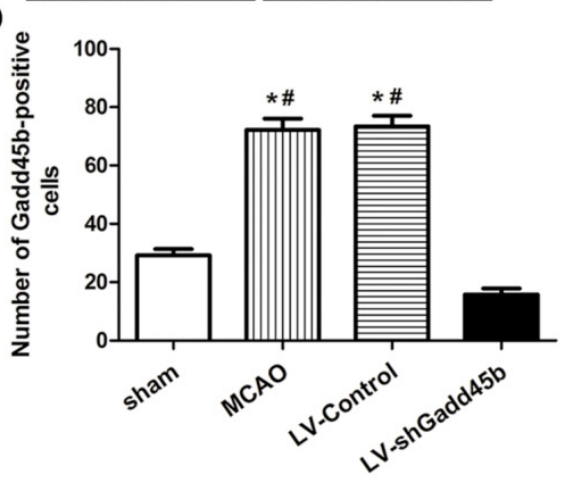

Figure 1. LV delivery efficacy and inhibition efficiency. Three different titers of LV-shGadd45b were injected $7 \mathrm{~d}$ before MCAO through stereotactic surgery. (A) A few GFP-positive cells were localized in the cortex and hippocampus injected with low-titer LVs. A large number of GFP-positive cells were observed in the cortex and hippocampus injected with medium- and high-titer LVs. (B) Gadd45b-shRNA treatment effectively suppressed MCAO-induced Gadd45b expression. Data were expressed as fold of sham. (C) Immunohistochemistry for Gadd45b (original magnification 400x). Images are taken from ipsilateral ischemic penumbra. (D) The bar graph reflects the Gadd45b-positive cells in each group. ( $\mathrm{p}<0.01$, compared with sham group, ${ }^{\#} \mathrm{p}<0.01$, compared with LV-shGadd45b group). after reperfusion. The brains were rapidly removed. Coronal sections ( $\mathrm{n}=6$ in each group) were cut into 2 $\mathrm{mm}$ thick slices and stained with standard $2 \%$ TTC for $20 \mathrm{~min}$ at $37^{\circ} \mathrm{C}$. The pale-appearing infarcted areas and areas of the uninfarcted hemispheres were digitally analyzed using NIH Image J software. The area of infarction from each slide was added and presented as a percentage of the volume of the uninfarcted hemisphere.

\section{TUNEL Assay}

TUNEL staining was done on brain section to detect cell apoptosis according to the manufacturer's protocol of an in situ cell death detection kit (Roche, Basel, Switzerland). TUNEL-positive cells were quantified by individual counts in sequential fields of 1 $\mathrm{mm}^{2}$ at ipsilateral ischemic penumbra in five rats selected randomly from each group. The TUNEL-positive cell number per field for each sample was the average of 20 consecutive objects in 4 sections/case by an investigator who was blinded to the studies.

\section{Statistical Analysis}

Data were expressed as means $\pm S D$. Differences between groups were compared using one-way analysis of variance (ANOVA). $\mathrm{P}<0.05$ was considered statistically significant. Statistical analysis was performed using SPSS 13.0 for Windows.

\section{Results}

\section{Delivery and Si- lencing Efficiency of shRNA LVs}

The titer of $\mathrm{LV}$ used was $6.9 \times 10^{8}$ $\mathrm{pfu} / \mathrm{ml}$. The titers of LV were categorized as $1.38 \times 10^{9} \mathrm{pfu} / \mathrm{ml}$ (high titer), $6.9 \times 10^{8}$ (medium titer), and $3.45 \times 10^{8}$ (low titer). The three titers were able to successfully transfect ipsilateral ischemic penumbra and ipsilateral hippocampus in the rat brains. Delivery efficacy was shown by GFP-positive cells. The 
transfection efficiency of medium and high titer injections were similar, and better than the efficiency of the low-titer group (Figure 1A).

Our previous study has shown that MCAO significantly increased Gadd45b expression in ipsilateral ischemic penumbra from $6 \mathrm{~h}$ to $72 \mathrm{~h}$ after focal cerebral ischemia [8]. This study showed that Gadd45b-RNAi significantly decreased MCAO-induced Gadd45b mRNA (Figure 1B, p <0.01) and protein (Figure $1 C, D, p<0.01$ ) expression in comparison to MCAO and LV-Control groups.

\section{Gadd45b-RNAi increased cerebral infarction and worsened neurological scores}

Infarct volume was measured $24 \mathrm{~h}$ after reperfusion. No infarction was observed in the sham group, whereas extensive lesion was developed in the striatum and lateral cortex in the LV-Control and MCAO groups. Gadd45b-RNAi significantly increased infarct volume in comparison to rats in LV-Control and

MCAO groups (Figures 2A, B, p<0.05). The effect of Gadd45b-RNAi in neurological deficits was also investigated. No neurological deficiency was observed in the sham group. The rats exhibited focal neurological deficiency following MCAO with failure to fully extend the forepaw. Treatment with Gadd45b-RNAi showed a significant increase in neurological score (Figure 2C, $\mathrm{p}<0.05$ ), indicating that Gadd45b-RNAi can worsen neurological deficits.

\section{Gadd45b-RNAi increased neuronal apoptosis after cerebral ischemia}

The apoptotic activity shown by TUNEL was a common method for detecting DNA fragmentation that results from apoptotic signaling cascades. A small number of TUNEL-positive cells were found in the sham-operated animals. In samples collected from the MCAO and LV-Control group, a large number and density of TUNEL-positive staining was found and further enhanced by Gadd45-RNAi treatment (Figure 3, p<0.01).

A
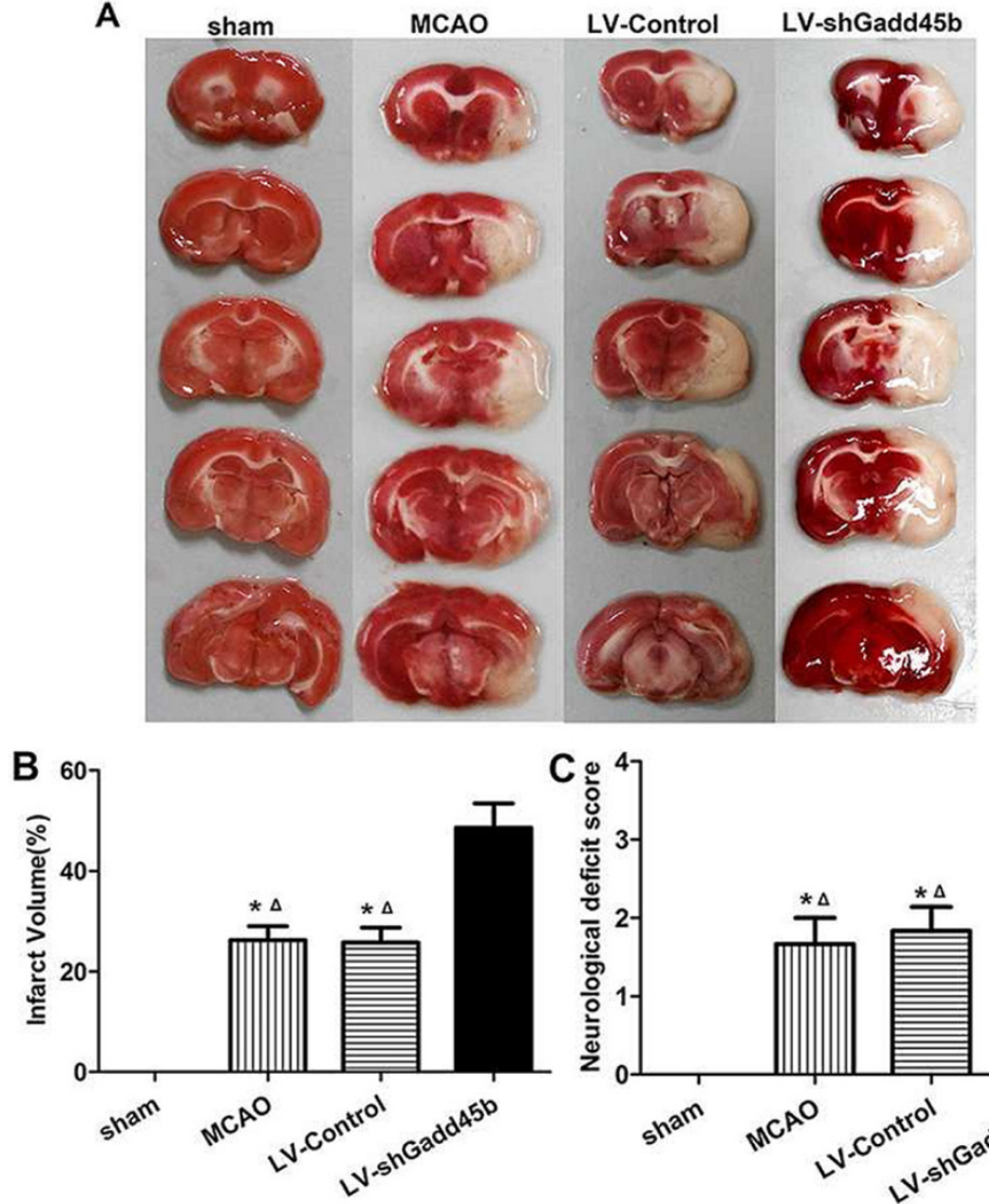

Figure 2. Gadd45b-RNAi treatment increased infarct size and worsened the neurological behavior at $24 \mathrm{~h}$ after reperfusion. (A) TTC staining of the brain. (B) The bar graph reflects the infarct volume in each group. (C) Determination of neurological deficits. ( ${ }^{*}<0.01$, compared with sham group, ${ }^{\Delta} \mathrm{p}<0.05$, compared with LV-shGadd45b group).

\section{Gadd45b-RNAi upregulated the apoptotic and down- regulated anti-apototic proteins}

Considering the importance of Bcl-2, Bax, and cleaved caspase- 3 in the regulation of neuronal apoptosis, the effects of Gadd45b-RNAi on these protein levels were determined. Immunochemistry analysis of the ipsilateral ischemic penumbra showed a strong upregulation of $\operatorname{Bax}(p<0.01$, Figure $4 \mathrm{~A}, \mathrm{~B})$ following MCAO as well as in the LV-Control group, and it was enhanced by Gadd45b-RNAi $(p<0.05)$. Immunochemistry analysis of the ipsilateral ischemic penumbra showed a strong downregulation of Bcl-2 ( $p<0.01$, Figure 4A, B) following MCAO as well as in the LV-Control group, but it was markedly inhibited by Gadd45b-RNAi $(p<0.05)$. Western blot analysis of the ipsilateral ischemic penumbra in each group showed that the expression levels of Bax (Figure 5A, B) and cleaved caspase-3 ( Figure $5 \mathrm{~A}, \mathrm{~B})$ were significantly increased in the MCAO and 
LV-Control groups compared to those of the sham group $(\mathrm{P}<0.05)$. Gadd45b-RNAi enhanced the levels of cleaved caspase- 3 and Bax proteins $(\mathrm{P}<0.05)$. The protein levels of Bcl-2 were significantly decreased in the MCAO and LV-Control groups compared to those of the sham group $(\mathrm{P}<0.05)$, and Gadd45b-RNAi further decreased the levels of $\mathrm{Bcl}-2$ protein $(\mathrm{P}<0.05)$.

\section{Gadd45b-RNAi decreased expression of the neuro-protective agent BDNF}

BDNF activation was shown to upregulate Bcl-2, downregulate Bax, inhibit caspase-3 activation and subsequent apoptosis following cerebral ischemia [11,12]. Gadd45b was shown to regulate BDNF expression in brain [13]. To further evaluate the mechanism of Gadd45b in apoptosis, we investigate the effect of Gadd45b-RNAi on BDNF expression. The changes in BDNF protein and mRNA levels were studied through immunohistochemistry, real-time PCR, and Western blot analysis $24 \mathrm{~h}$ after focal cerebral ischemia. The brain BDNF levels are shown in Figure 6. In ipsilateral ischemic penumbra, immunohistochemical studies showed that expression of BDNF-positive cells $(p<0.01$, Figure $6 \mathrm{~A}, \mathrm{~B})$ increased after cerebral ischemia. Gadd45b-RNAi decreased BDNF-positive cells in comparison to MCAO and LV-Control groups $(\mathrm{p}<0.01)$. The BDNF protein levels, determined by Western blot analysis, reflected the immunohistochemical results in the same region $(p<0.01$, Figure $6 \mathrm{D}, \mathrm{E})$. Moreover, in ipsilateral ischemic penumbra, the mRNA levels of BDNF were consistent with the protein levels in each group $(p<0.01$, Figure 6C).

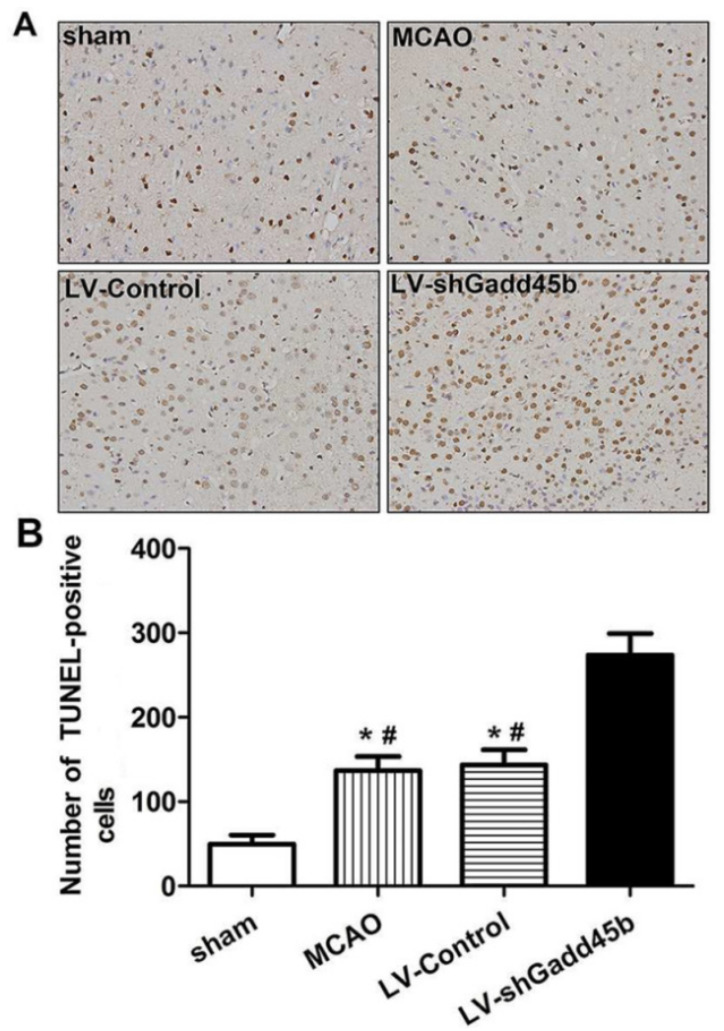

Figure 3. Gadd45b-RNAi treatment increased cell apoptosis in cerebral ischemia. (A) TUNEL assay after cerebral ischemia (original magnification 400x). (B) The bar graph reflects the TUNEL-positive cell number in ipsilateral ischemic penumbra in each group. ( $\mathrm{p}<0.01$, compared with sham group, ${ }^{\#} \mathrm{p}<0.01$, compared with LV-shGadd45b group).
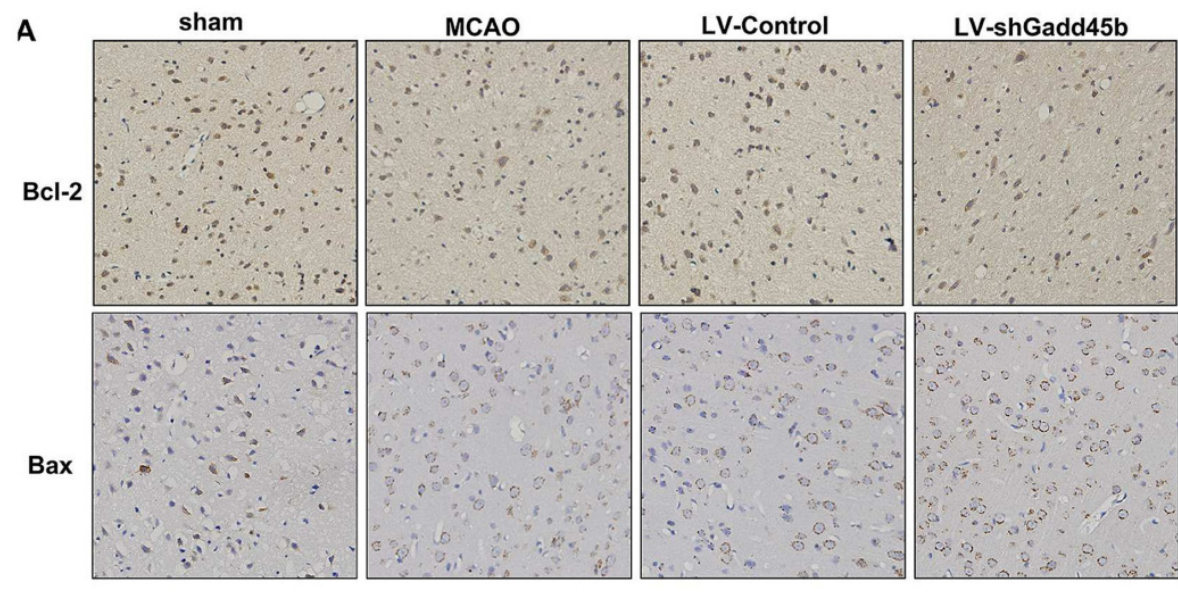

Figure 4. Immunohistochemical analysis of Bax and $\mathrm{Bcl}-2$ expression in stroke rats. (A) Immunohistochemistry for $\mathrm{Bax}$ and $\mathrm{Bcl}-2$ (original magnification 400x). Images are taken from ipsilateral ischemic penumbra. (B) The bar graph reflects the $\mathrm{Bcl}-2$ and Bax-positive cells in each group. (* $\mathrm{p}<0.01$, compared with sham group, ${ }^{\#} \mathrm{p}<0.01$, compared with LV-shGadd45b group, ${ }^{\Delta} \mathrm{p}<0.05$, compared with LV-shGadd 45 b group).
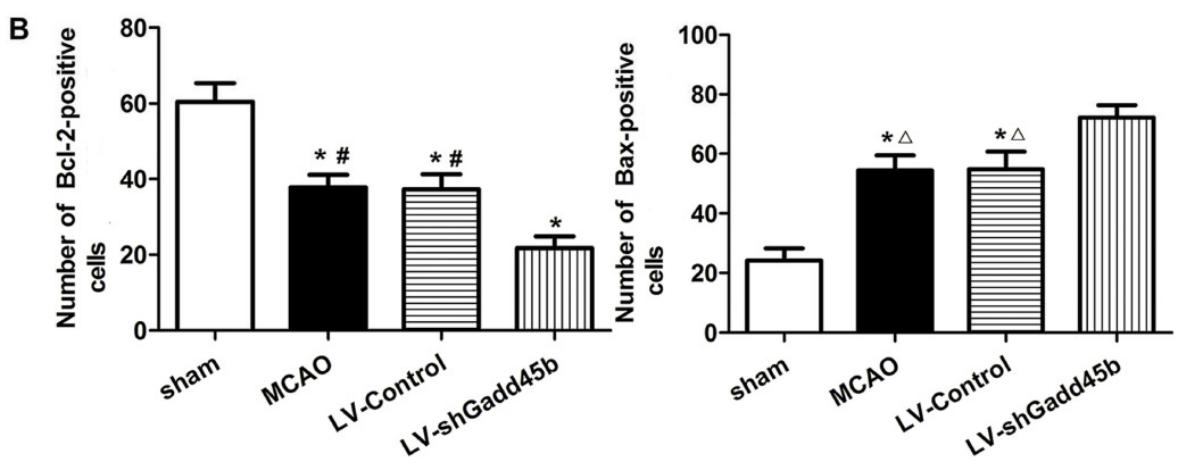


\section{DISSCUSSION}

The aim of this study was to determine the role of Gadd45b on apoptosis during focal cerebral ischemia. In the present study, a previously unknown, intrinsic, anti-apoptotic molecule Gadd45b in ischemic brain was elucidated. Research on enhancing the neuroprotective function of Gadd $45 \mathrm{~b}$ may provide effective therapeutic strategies for preventing the death of the neurons in stroke.

Apoptosis plays an essential role in the acute and chronic phases of ischemic stroke [14,15]. Many studies have shown that inhibition of apoptosis has a beneficial effect in acute ischemic stroke process. The genes responsible for ischemic stroke-induced neuronal cell death have not been fully identified, although various studies have sought to elucidate the molecular basis of acute ischemic stroke. Our results in this study demonstrated that Gadd45b is essential for ischemic stroke-induced neuronal apoptotic death based on the following evidence. First, our previous study showed that mRNA and protein levels of Gadd45b were significantly increased by transient cerebral ischemia in ischemic brain [8]. Second, ischemic stroke-induced neuronal death was remarkably aggravated by the down-regulation of Gadd45b.

Gadd45 is a highly conserved three-gene family consisting of Gadd45a, Gadd45b, and Gadd45g. Gadd45 has been identified as a stress-response gene to physiological or environmental conditions, and is originally induced by genotoxic agents [16]. Gadd45a has been demonstrated as a pro-apoptosis gene in neuronal injuries $[17,18]$ and Gadd45b has been implicated as an anti-apoptosis factor. The present research showed that Gadd45b inhibits neuronal apoptosis after cerebral ischemia. Gadd45b is significantly involved in preventing RGC death [5,6], which is consistent with our findings regarding its anti-apoptotic role in neurons. Gadd45b also inhibits apoptosis in other cell types, such as NIH3T3 and INS-1Eb cells $[19,20]$. By contrast, Gadd $45 b$ was found to induce apoptotic death in cardiomyocytes [21], murine hepatocytes [22,23], and other cell types [24]. Accordingly, the function of Gadd45b in apoptosis appears to be cell type specific. Apoptosis occurs after acute ischemic stroke, and is regulated by the apoptotic and anti-apoptotic proteins of the Bcl-2 family. Pro-survival Bcl-2 proteins include Bcl-2 and Bcl-xL, as well as pro-apoptotic proteins including Bax, Bad, and Bak $[25,26]$. The relative amounts of active antiand pro-apoptotic $\mathrm{Bcl}-2$ family proteins determine the resistance of the cells to apoptosis. Increased Bcl-2 expression with a concurrent decrease of Bax mainly functions in protecting the brain against apoptosis induced by acute ischemic stroke [27]. Caspase-3 is also a well-identified pro-apoptotic executioner that is involved in apoptosis [28]. Several groups have provided evidence that activation of caspase- 3 is involved in neurons undergoing ischemic cell death [29]. As demonstrated in the present study, Gadd $45 \mathrm{~b}$ down regulation increased brain damage following ischemic stroke. The increase in brain damage is associated with increased apoptosis as indicated by increased levels of Bax and active caspase-3, and decreased levels of Bcl-2.

Many animal studies have documented the anti-apoptotic capability of BDNF in experimental ischemic stroke. BDNF reduces neuronal death after transient forebrain ischemia in vivo [30,31]. Intravenous BDNF counterregulates the expression pro-apoptotic Bax and anti-apoptotic Bcl-2 proteins after focal cerebral ischemia [11]. BDNF also inhibits caspase-3 activation and subsequent apoptosis following hypoxic-ischemic injury [12]. Previous studies have clearly showed that activation of BDNF-associated signaling pathways inhibits neuronal apoptotic cell death.

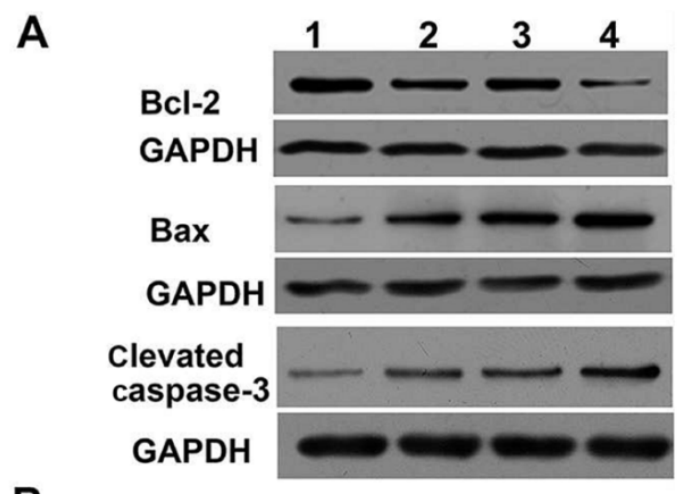

B
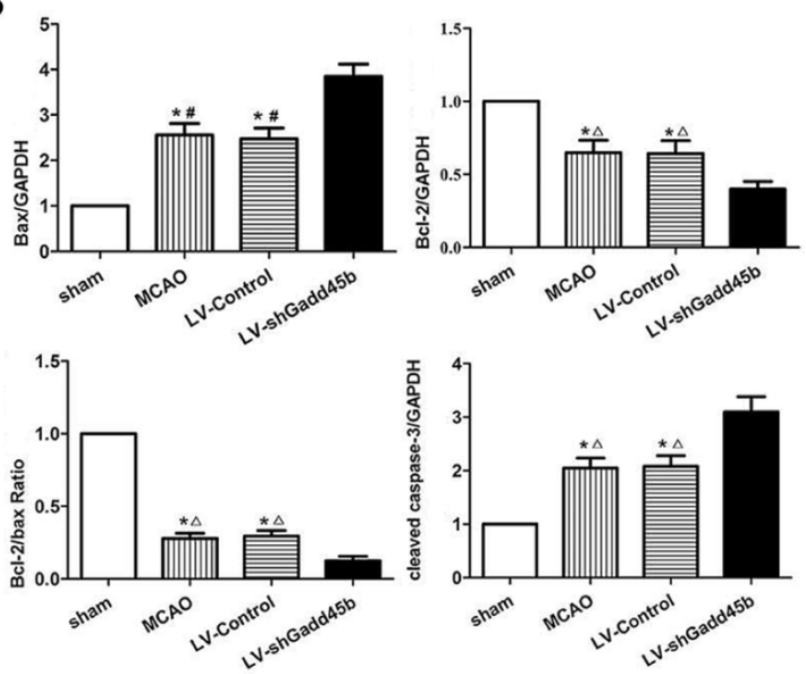

Figure 5. Protein levels of cleaved caspase-3, Bax, and $\mathrm{Bcl}-2$ in stroke rats. (A) Western blot assay of cleaved caspase-3, Bax, and $\mathrm{Bcl}-2$ expression. 1: sham group; 2: MCAO group; 3: LV-Control group; 4: LV-shGadd45b group. (B) The bar graph reflects the cleaved caspase-3, Bax, and $\mathrm{Bcl}-2$ protein expressions in each group. Data were expressed as fold of sham. (" $\mathrm{p}<0.01$, compared with sham group, ${ }^{\#} \mathrm{p}<0.01$, compared with LV-shGadd 45 b group, ${ }^{\Delta} \mathrm{p}<0.05$, compared with LV-shGadd45b group). 


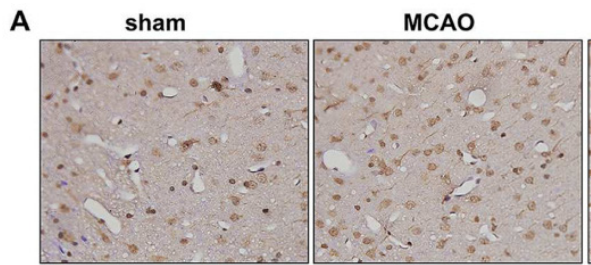

LV-Control

LV-shGadd45b
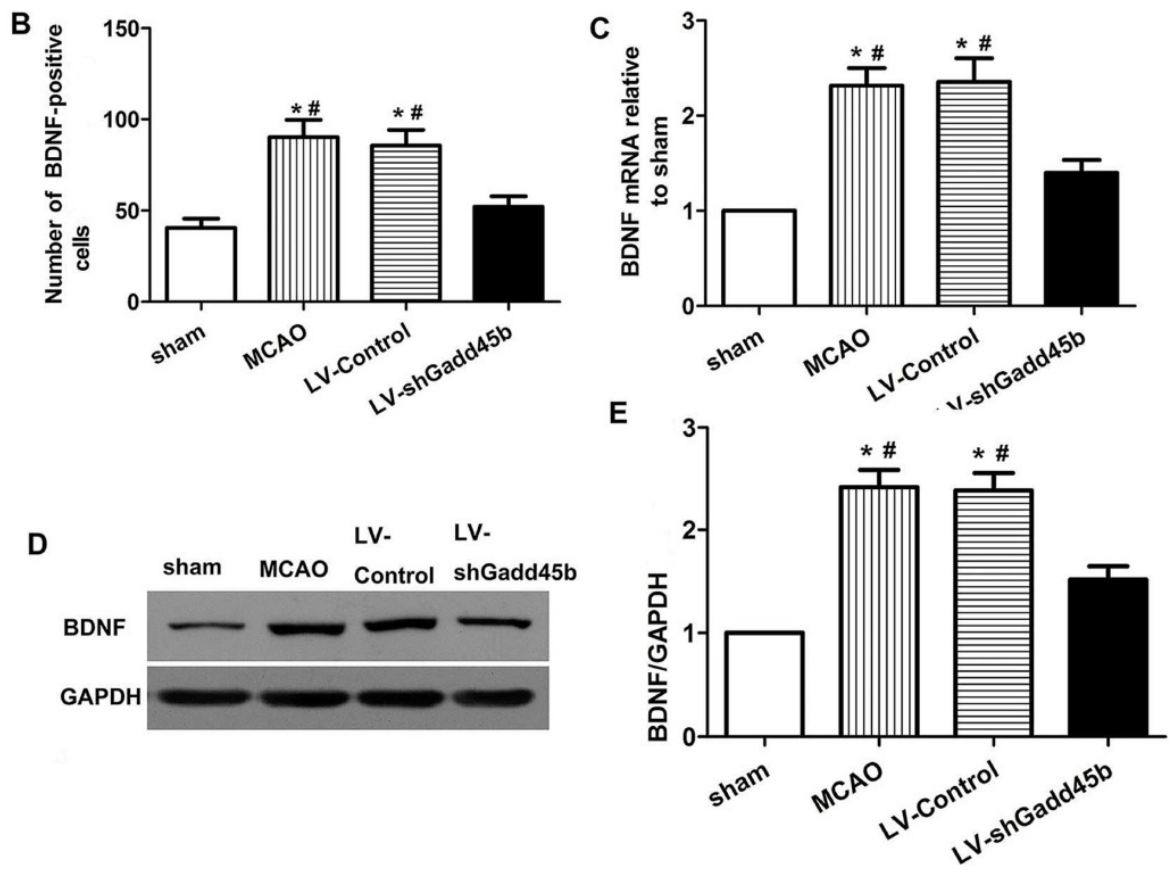

Figure 6. Gadd45b-RNAi treatment suppressed BDNF expression $24 \mathrm{~h}$ after MCAO. (A) Immunohistochemistry for BDNF (original magnification $400 \times$ ). Images are taken from ipsilateral ischemic penumbra. (B) The bar graph reflects the BDNF-positive cells in each group. (C) The bar graph reflects the BDNF mRNA expression in each group. Data were expressed as fold of sham. (D) Western blot assay of the BDNF expression in each group. (E) The bar graph reflects the BDNF protein expressions in each group. Data were expressed as fold of sham. (" $\mathrm{p}<0.01$, compared with sham group, \#p<0.05, compared with LV-shGadd45b group).

Gadd45b reduces brain apoptosis, but the mechanism of Gadd45b in apoptosis is not clear. As is shown in this study, Gadd45b may regulates apoptosis by regulating BDNF and downstream regulatory apoptotic proteins in ischemic stroke. First, Gadd45b promoteregulatess DNA demethylation of the regulatory regions of BDNF. Gadd45b knockout mice show a decrease in BDNF gene expression. Neurons lacking Gadd45b fail to demethylate DNA, thereby failing to activate BDNF by previous studies $[13,32]$ and our recent research [33]. Second, many previous studies have clearly showed that activating BDNF-associated apoptotic proteins inhibits neuronal apoptotic cell death. Thirdly, this study indicated that Gadd45b-RNAi treatment obviously down regulated BDNF expression and subsequent apoptosis after ischemic brain injury.

Decreased BDNF levels may related to the decreased demethylation of BDNF by Gadd45b down regulation. Despite all this, the role of BDNF in Gadd45b-mediated apoptosis was not clear. Therefore, it would be interesting to show whether the down regulation of BDNF affect the role of Gadd $45 b$ in neuronal apoptotic cell death.
In summary, this study indntify Gadd $45 \mathrm{~b}$ as a critical mediator of cerebral ischemia-induced neuronal apoptotic death. Our findings suggest that treatment strategies targeting Gadd $45 \mathrm{~b}$ could be used to inhibit neuronal apoptotic cell death after acute ischemic stroke.

\section{Abbreviations}

Gadd45b, Growth Arrest and DNA-Damage-inducible protein 45 beta; MCAO, middle cerebral artery occlusion; RNAi, RNA interference; LV, lentiviral vectors; CCA, common carotid artery; ECA, external carotid artery; ICA, internal carotid artery; GFP, Greenfluorescent protein; TTC, triphenyltetrazolium chloride; BDNF, brain-derived neurotrophic factor.

\section{Acknowledgement}

This work was supported by the Natural Science Foundation of China (Grant No. 81271306) and the Medical Science Research Project of Chongqing $\mathrm{Mu}-$ nicipal Health Bureau (2012-1-037). 


\section{Author Contributions}

Conceived and designed the experiments: BL CL. Performed the experiments: BL YZ GH. Analyzed the data: YJ. Contributed reagents/materials/analysis tools: LL XT. Wrote the manuscript: BL.

\section{Competing Interests}

The authors have declared that no competing interest exists.

\section{References}

1. Broughton BR, Reutens DC, Sobey CG. Apoptotic mechanisms after cerebral ischemia. Stroke. 2009; 40:e331-9.

2. Joza N, Susin SA, Daugas E, Stanford WL, Cho SK, et al. Essential role of the mitochondrial apoptosis-inducing factor in programmed cell death. Nature. 2001; 401:549-554.

3. Yamamoto Y, Negishi M. The antiapoptotic factor growth arrest and DNA-damage-inducible 45 beta regulates the nuclear receptor constitutive active/androstane receptor-mediated transcription. Drug Metab Dispos. 2008; 36:1189-93.

4. Yamamoto Y, Moore R, Flavell RA, Lu B, Negishi M. Nuclear Receptor CAR Represses TNFa-Induced Cell Death by Interacting with the Anti-Apoptotic GADD45B. PLoS One 2010; 5:e10121.

5. Liu B, Suyeoka G, Papa S, Franzoso G, Neufeld AH. Growth arrest and DNA damage protein $45 \mathrm{~b}$ (Gadd45b) protects retinal ganglion cells from injuries. Neurobiol Dis. 2009: 33:104-10.

6. Liu B, Sun X, Suyeoka G, Garcia JG, Leiderman YI. TGF $\beta$ signaling induces expression of Gadd45b in retinal ganglion cells. Invest Ophthalmol Vis Sci. 2013; 54:1061-9.

7. Belayev L, Alonso OF, Busto R, Zhao W, Ginsberg MD. Middle cerebral artery occlusion in the rat by intraluminal suture. Neurological and pathological evaluation of an improved model. Stroke. 1996; 27:1616-1622.

8. Liu B, Li J, Li L, Yu L, Li C. Electrical stimulation of cerebellar fastigial nucleus promotes the expression of growth arrest and DNA damage inducible gene $\beta$ and motor function recovery in cerebral ischemia/reperfusion rats. Neurosci Lett. 2012; 520:110-114

9. Livak KJ, Schmittgen TD. Analysis of relative gene expression data using real-time quantitative PCR and the 2(-Delta Delta C(T)) Method. Methods. $2001 ; 25: 402-408$

10. Hunter AJ, Hatcher J, Virley D, Nelson P, Irving E, Hadingham SJ, et al. Functional assessments in mice and rats after focal stroke. Neuropharmacology. 2010; 39:806-816.

11. Schäbitz WR, Sommer C, Zoder W, Kiessling M, Schwaninger M, et al. Intravenous brain-derived neurotrophic factor reduces infarct size and counterregulates Bax and Bcl-2 expression after temporary focal cerebral ischemia. Stroke. 2000; 31:2212-7.

12. Han BH, D'Costa A, Back SA, Parsadanian M, Patel Set, et al. BDNF blocks caspase-3 activation in neonatal hypoxia-ischemia. Neurobiol Dis. 2007; 7:38-53.

13. Ma DK, Jang MH, Guo JU, Kitabatake Y, Chang ML, et al. Neuronal activity-induced Gadd45b promotes epigenetic DNA demethylation and adult neurogenesis. Science. 2009; 323:1074-1077.
14. Legos JJ, Barone FC. Update on pharmacological strategies for stroke: Prevention, acute intervention and regeneration. Curr Opin Investig Drugs. 2003; 4:847-858.

15. Mitsios N, Gaffney J, Krupinski J, Mathias R, Wang Q, et al. Expression of signaling molecules associated with apoptosis in human ischemic stroke tissue. Cell Biochem Biophys. 2007; 47:73-86.

16. Liebermann DA, Hoffman B. Gadd45 in the response of hematopoietic cells to genotoxic stress. Blood Cells Mol Dis. 2007; 39:344-347.

17. Befort K, Karchewski L, Lanoue C, Woolf CJ. Selective up-regulation of the growth arrest DNA damage-inducible gene Gadd45 alpha in sensory and motor neurons after peripheral nerve injury. Eur J Neurosci. 2003; 18:911-922.

18. Uberti D, Meli E, Memo M. Expression of cell-cycle-related proteins and excitoxicity. Amino Acids. 2002; 23:27-30.

19. Larsen CM, Dossing MG, Papa S, Franzoso G, Billestrup N, et al. Growth arrest- and DNA-damage-inducible $45 \mathrm{~b}$ gene inhibits c-Jun N-terminal kinase and extracellular signal-regulated kinase and decreases IL-1beta-induced apoptosis in insulin-producing INS-1E cells. Diabetologia. 2006; 49:980-989.

20. Engelmann A, Speidel D, Bornkamm GW, Deppert W, Stocking C. Gadd45b is a pro-survival factor associated with stress-resistant tumors. Oncogene. 2008; 27:1429-1438.

21. Kim MY, Seo EJ, Lee DH, Kim EJ, Kim HS, et al. Gadd45beta is a novel mediator of cardiomyocyte apoptosis induced by ischaemia/hypoxia. Cardiovasc Res. 2010; 87(1):119-26.

22. Cho HJ, Park SM, Hwang EM, Baek KE, Kim IK, et al. Gadd45b mediates Fas-induced apoptosis by enhancing the interaction between p38 and retinoblastoma tumor suppressor. J Biol Chem. 2010; 285:25500-5.

23. Yoo J, Ghiassi M, Jirmanova L, Balliet AG, Hoffman B, et al. Transforming growth factor-b-induced apoptosis is mediated by Smad-dependent expression of GADD45b through p38 activation. J Biol Chem. 2003; 278:43001-43007.

24. Takekawa M, Saito H. A family of stress-inducible GADD45-like proteins mediate activation of the stress-responsive MTK1/MEKK4 MAPKKK. Cell. 1998; 95:521-30.

25. Lazou A, Iliodromitis EK, Cieslak D, Voskarides K, Mousikos S, et al. Ischemic but not mechanical preconditioning attenuates ischemia/reperfusion induced myocardial apoptosis in anaesthetized rabbits: the role of $\mathrm{Bcl}-2$ family proteins and ERK1/2. Apoptosis. 2006; 11:2195-2204

26. Mayer B, Oberbauer R. Mitochondrial regulation of apoptosis. News Physiol Sci. 2003; 18:89-94.

27. Rybnikova E, Sitnik N, Gluschenko T, Tjulkova E, Samoilov MO. The preconditioning modified neuronal expression of apoptosis-related proteins of Bcl-2 superfamily following severe hypobaric hypoxia in rats. Brain Res. 2006; 1089:195-202.

28. Budihardjo I, Oliver H, Lutter M, Luo X, Wang X. Biochemical pathways of caspase activation during apoptosis. Annu Rev Cell Dev Biol. 1999; 15:269-290.

29. Namura S, Zhu J, Fink K, Endres M, Srinivasan A, et al Activation and cleavage of caspase- 3 in apoptosis induced by experimental cerebral ischaemia. J Neurosci. 1998; 18:3659-3668.

30. Beck T, Lindholm D, Castren E, Wree A. BDNF protects against ischemic cell damage in rat hippocampus. J Cereb Blood Flow Metab. 1994; 14:689 -692.

31. Tsukahara T, Yonekawa Y, Tanaka K, Ohara O, Wantanabe S, et al. The role of BDNF in transient forebrain ischemia in the rat brain. Neurosurgery. 1994; 34:323-330.

32. Gavin DP, Sharma RP, Chase KA, Matrisciano F, Dong E, et al. Growtharrest and DNA-damage-inducible, beta (GADD45b)-mediated DNA demethylation in major psychosis. Neuropsychopharmacology. 2012; 37:531-42.

33. Liu B, Li LL, Tan XD, Zhang YH, Jiang Y, et al. Gadd45b Mediates Axonal Plasticity and Subsequent Functional Recovery After Experimental Stroke in Rats. Mol Neurobiol. 2014; Oct 17. 